PERIODICALS OF ENGINEERING AND NATURAL SCIENCES

Vol. 5 No. 1 (2017) - Special Issue (Recent Topics in Environmental Science)

Available online at: http://pen.ius.edu.ba

\title{
THE EFFECT OF SEALING SYSTEM ON ZERO FUGITIVE EMISSIONS AND GLOBAL WARMING
}

\author{
Adem CALISKAN, Adem ONAT \\ *Sakarya University, Vocational School of Sakarya, 54188 SAKARYA - TURKEY
}

\begin{abstract}
Nowadays keeping the air clean is one of the most important aims in environmental protection. The fugitive emissions especially Volatile Organic Compounds (VOC's) and the ozone-precursors nitrogen oxides $\left(N O_{X}\right)$ have a great impact on the quality of the atmospheric air. Worldwide fugitive emissions from leaking valves, pumps and flanges amount to over a million metric tonnes per year. Elimination or reduction of fugitive emissions could save industry many millions of dollars and prolong scarce resources.
\end{abstract}

Sealing system is the major contributing factor will be through the lowering of fugitive emissions. In this study, various kind of fibre reinforced Nitrile Butadiene Rubber (NBR) sheet sealing materials and new developed expanded graphite sheets were investigated. Experimental results shown that, the sealing performance has been improved by the development in material technologies. Fibre base materials have higher permeability than expanded graphite for both liquid and gas environments. They have adequate sealing performance to need for all over applications. Expanded graphite shows better sealing performance than fibre base materials but it has lower recovery.

As a result, for every specific application, careful selection, correct installation and operation according to the performance envelope, regular inspection and maintenance must be considered for low or zero emission requirements.

Keywords: Fugitive Emission; Global Warming; Volatile Organic Compound; Sealing Materials; Characterization; Sealing Performance

\section{Introduction}

It is recognised that industry must reduce its impact on the environment if we are to continue global development for future generations. A major contributory factor will be through the lowering of industrial emissions, which has been catalysed by a combination of public pressure, environmental legislation and the internal requirement to minimise the loss of valuable feed-stocks. Large proportions of the emissions to atmosphere are represented by the by-products of combustion (notably the oxides of carbon, nitrogen and sulphur), along with known losses of Volatile Organic Compounds (VOC's) and steam. In general, these are all emissions anticipated from the industrial process, under the control of the plant operator [1-3].

The fugitive emission is often defined as; any chemical, or mixture of chemicals, in any physical form, which represents an unanticipated or spurious leak, from anywhere on an industrial site [1-3]. It also covers all losses of materials (usually volatile) from a process plant, through evaporation, flaring, spills and unanticipated or spurious leaks [1].

The fugitive emissions especially VOC's are of significant environmental concern because some have the potential for Photochemical Ozone Creation Potential (POCP), Ozone Depletion Potential (ODP), Global Warming Potential (GWP), toxicity, carcinogenicity and local nuisance from odour. These properties mean that VOC's are a major contributor to the formation of "Summer Smog". The prevention of VOC emissions is therefore one of the most important issues facing the operation of many industrial processes $[1,4,5]$.

VOC is the generic term applied to those organic carbon compounds which evaporate at ambient temperature, and is defined usually as " a substance having a vapour pressure of greater than $0.3 \mathrm{kPa}$ at $20^{\circ} \mathrm{C}$ ". The term covers a 
diverse group of substances and includes all organic compounds released to air in the gas phase, whether hydrocarbons or substituted hydrocarbons. Their properties, and hence need for control, vary greatly and so systems have been developed to categorise VOC's according to their harmfulness. The three classes are [1]:

- Extremely hazardous to health (such as benzene and vinyl chloride)

- Class A compounds, which may cause significant harm to the environment (e.g., acetaldehyde, aniline and benzyl chloride)

- Class B compounds, which have lower environmental impact

Some VOC's may also be highly odorous, for example aldehydes, amines, mercaptans and other sulphurcontaining compounds. This may necessitate additional stringency in the prevention measures (e.g. high integrity equipment to reduce fugitives) and the abatement of losses.

To put the scale of the challenge into perspective, fugitive emissions in the USA have been estimated to be in excess of 300,000 tonnes per year, accounting for about one third of the total organic emissions from chemical plants, and inevitably mirrored in Europe. Irrespective of any environmental impact which it may cause, this is a tremendous financial burden on industry because it represents a huge loss of potentially valuable materials, and cause of plant inefficiency [4]. Yet in most instances, the true costs are not appreciated, since many of the costs associated with fugitive emissions are invisible (Figure 1) [1-4]. The values of fugitive emissions will depend upon $[1,2]$ :

- Equipment design

- Age and quality of the equipment

- Standard of installation

- Vapour pressure of the process fluid

- Process temperature and pressure

- Number and type of sources

- Method of determination

- Inspection and maintenance routine

- Rate of production

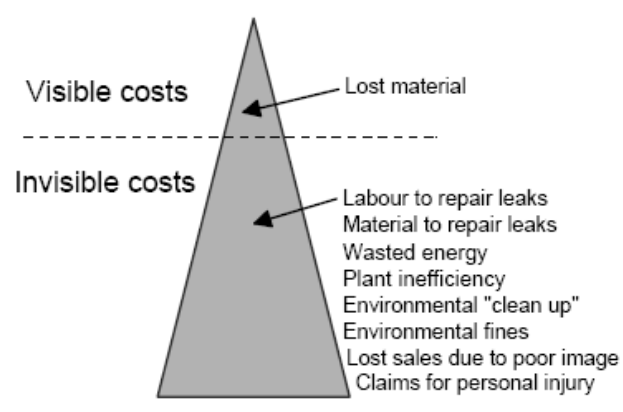

Figure 1. The sources and costs of fugitive emissions [1-4]

A significant proportion of fugitive emissions can be losses from unsealed sources, including storage of liquid and gas tanks, open-ended (non-blanked) lines, pressure-relief valves, vents, flares, blow-down systems, spills and evaporation from water treatment facilities. These are part of the industrial process, usually anticipated by the process operator. In other cases, these losses may be caused by leaks in the sealing elements of particular items of equipment, such as [1]:

- Agitators / Mixers

- Compressors

- Flanges

- Pumps

- Tank Lids

- Valves
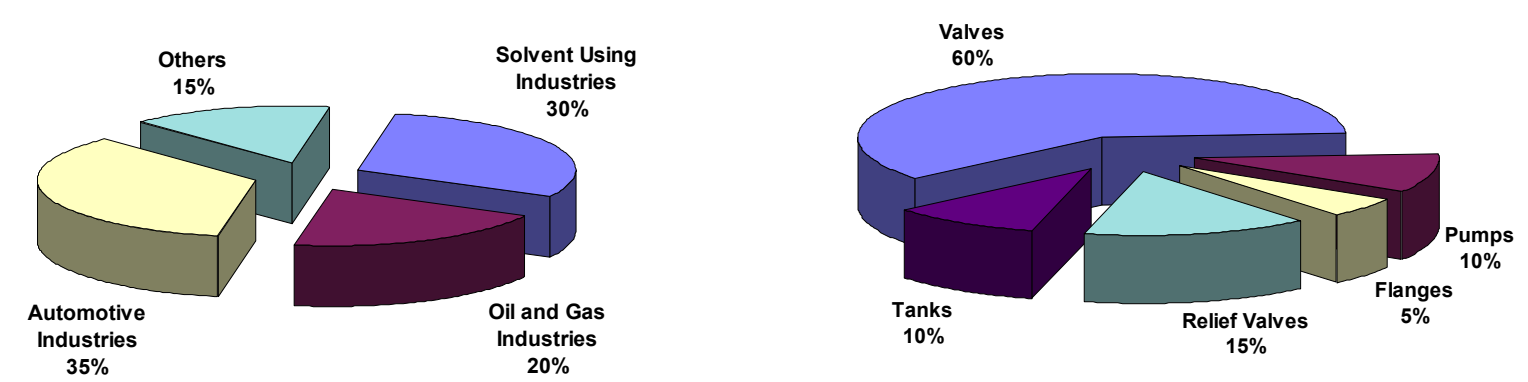

Figure 2. Fugitive emissions by source type [3] 
As can be seen Figure 2, valves are considered to account for approximately 50-60\% of fugitive emissions. Furthermore, the major proportion of fugitive emissions comes from only a small fraction of the sources [1-4]. Leaking losses are often hard to determine since there are many potential sources and they are very dependent on how well the installation is operated, maintained and inspected. Some important causes of leaking losses are [1]:

- Ill-fitting sealing elements

- Installation faults

- Construction faults

- Wear and tear

- Ageing

- Equipment failure

- Contamination of the sealing element

- Excursions out of normal process conditions

- Poor maintenance procedures

Sealing systems play a vital role in the environmental performance of industrial installations. After careful selection appropriate for the specific application, correct installation, and operation according to the performance envelope, regular inspection and maintenance must be considered for low or zero emission requirements.

A seal is a basically a device closing (sealing) a gap or making a joint-tight the fluid in this case being either a gas or liquid $[6,7]$. The primary purpose of a seal is to contain a fluid and so protect the immediate environment from contamination and vice versa [8]. This may vary in significance from innocuous fluid loss such as steam and water up to nauseous, toxic or hazardous fluid loss. In the former case, the loss of such innocuous fluid will lead primarily to lack of plant efficiency for the operator, although such leakages may still present hazards such as leakages of high pressure water or steam. Clearly, in the latter case it is not only financially inefficient but also environmentally dangerous; for employees, members of the public and for nature at large! Consequently, the correct selection and use of the appropriate sealing technology for the application is just part of the environmental responsibility of the plant operator.

Sealing takes place between surfaces which do not move relative to one another in static seals or gaskets whereas a dynamic seal where sealing takes place between surfaces which have relative movement $[6,9]$.

It is possible to say that a static seal or gasket is one of the most important mechanical construction parts of each kind of machines and transport systems used in automotive and aerospace industry, piping systems and petrochemical industry [10-12].

\section{Experimental Studies}

In this study, parameters affecting system performances to elimination of fugitive emissions were determined and effects of variations on these parameters on sealing performance and mechanical properties are characterised according to tests given by ASTM, DIN, BSI standards. For this aim the widespread used soft gasket materials, have $0.80 \mathrm{~mm}$ thickness, were investigated in experimental studies. For this aim, fibre based static sealing materials widespread using in sealing applications were determined then procured. Also new developed expanded graphite sheet materials were used for characterisation.

Experimental equipment's were designated and manufactured according to international standards. Also test samples were prepared in steel cutting moulds to achieve close tolerance. Before every test five samples were conditioned as specified for particular type of material and tests according to relevant standards.

\section{Results and Discussions}

The important sealing materials properties affecting system performance and fugitive emissions are discussed below:

a) Density is the one of the most important properties affecting sealing performance. It is given by calculation of the grams of material in a cubic centimetre $\left(\mathrm{g} / \mathrm{cm}^{3}\right)$. The sealing ability depends on the porosity amount of materials. Generally, the higher the density gives the better the performance. But sealing elements must be compressible enough to fill surface irregularities of flanges. Average densities of sealing materials used in experimental studies are given in Figure 3. 


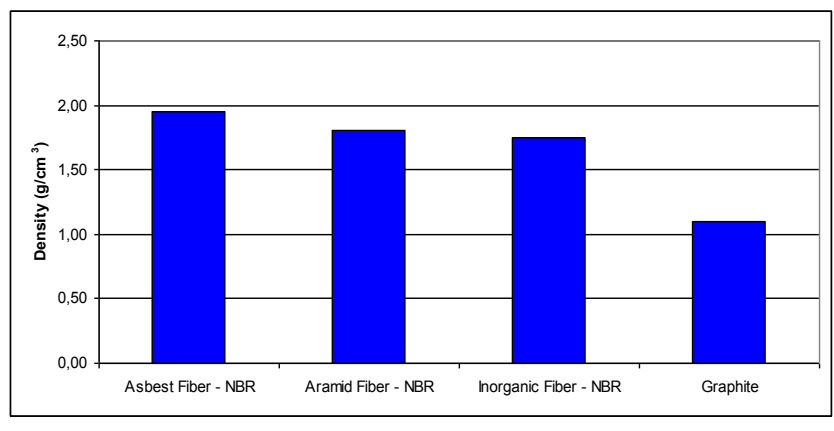

Figure 3. Density of selected gasket material types

As can be seen the above figure new developed graphite base materials have lover density from the other commercial materials. Also it is clear that as the sealing materials technology develops, density decreases. On the other hand, in the international sealing literatures sealing materials can be classified into three groups according to their density:

1. Low density (lower than $0.88 \mathrm{~g} / \mathrm{cm}^{3}$ ): Offer high degree of conformability for used or scratched flanges that are often encountered in the aftermarket or service industries. Generally, lower density materials don't seal as well as high density material, and don't have sufficient torque retention for the more demanding applications of global OEM manufacturers. In this investigation all of samples have low density.

2. Medium density (between $0.88 \mathrm{~g} / \mathrm{cm}^{3}$ and $1.36 \mathrm{~g} / \mathrm{cm}^{3}$ ): $\quad$ Offers a balance or compromise between low and high density. These materials are acceptable for OEM use and offer the necessary sealability and torque retention capability. Used in joints that does not require mechanical integrity or outstanding sealability. In this study, only graphite base material is in this group.

3. High density (greater than $1.36 \mathrm{~g} / \mathrm{cm}^{3}$ ): $\quad$ These materials are less compressible and suited for applications with uniform flange pressures, since these materials will not conform well to flanges that bend or distort. High density materials have excellent sealability, crush resistance and torque retention. Suitable for most OEM applications. The asbestos and aramid fibre base sealing materials in this investigation are suitable for this criteria widespread used material in the world.

b) Sealability is probably the most important of all gasket properties, because it measures the primary function of a gasket's ability to seal. It is a measure of how much fluid escapes from a controlled flange surface and measured as a leakage rate, generally in $\mathrm{ml} / \mathrm{h}$.

Standard ASTM testing used ASTM Fuel A or Nitrogen as the fluid, with the flange being a very smoothly finished steel surface (thus evaluating leakage through the material only and takes flange surface condition out as a variable).

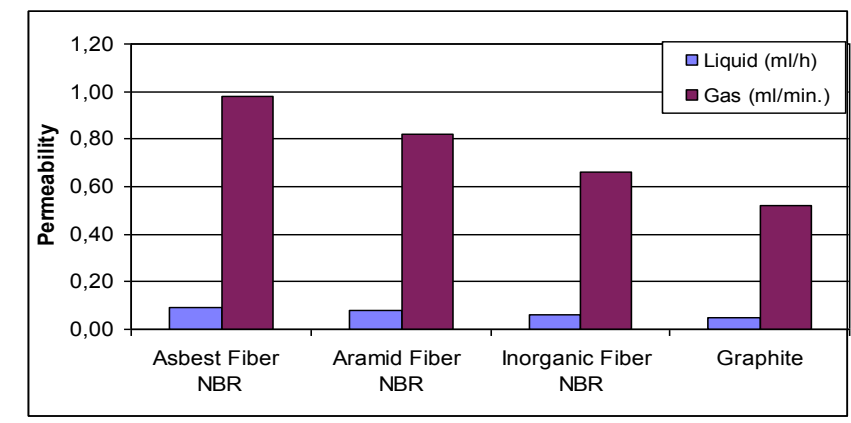

Figure 4. Leakage rates of selected gasket material types

c) Compressibility is expressed in percentage; it is a measure of how much the thickness of a material changes under a given load, compared to its original thickness. Compressibility properties of gasket materials vary depending upon the type of material and the applications for which they are intended.

In order to function effectively, a gasket material must be somewhat compressible. This is necessary for two reasons. First, the gasket material must be able to conform to surface irregularities of flanges. Second, in the case of fibrous sheets, the gasket material must be sufficiently compressible to close the pores and render the material 
impermeable for sealing purposes. In addition, however, the gasket material must not be so soft as to easily crush or creep [13].

d) Recovery is expressed in percentage; it is a measure of the resiliency of the material. The number indicates the percentage of "spring back" of the material after it has been compressed under a given load. For example, a material with $20 \%$ recovery means it regains $20 \%$ of the thickness it lost after being compressed under a given load.

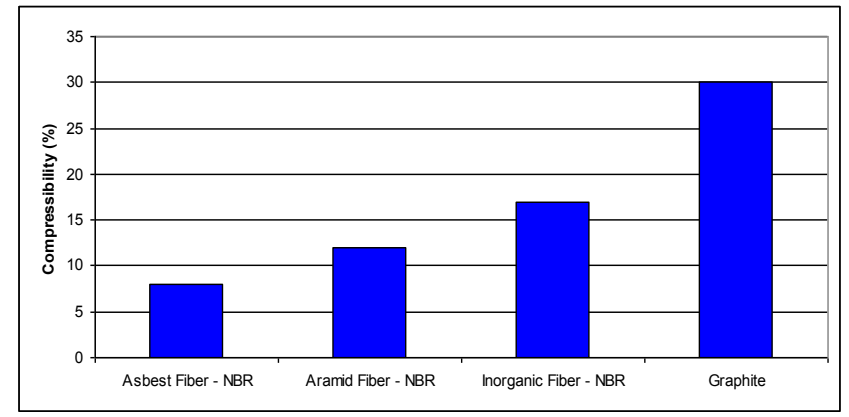

Figure 5. Compressibility of selected gasket material types

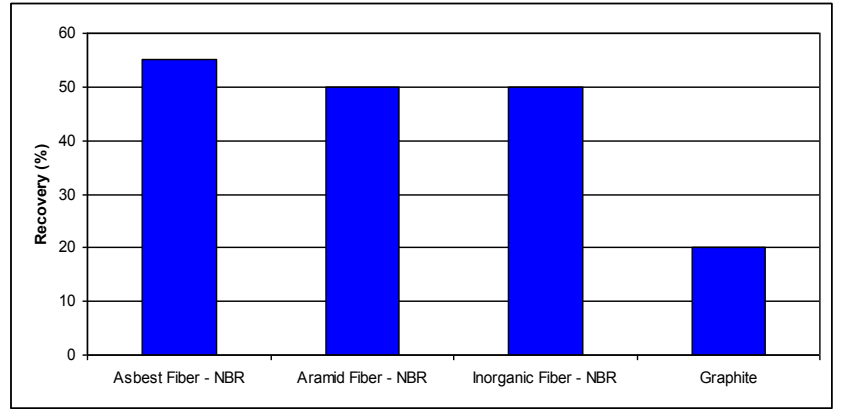

Figure 6. Recovery of selected gasket material types

Once compressed, most gasket materials do not act like perfect springs. If the compressive load on gasket materials is removed immediately after application, the material will usually not totally re expand to its full initial thickness ( $100 \%$ recovery). Rather, the gasket material takes a partial compression set and recovers only partially. The amount of recovery and the residual compressive strength of a gasket can be crucially important in applications involving thermal cycling or vibration that can cause flanges to move with respect to each other.

On seating, a gasket must be capable of overcoming minor alignment and flange imperfections, such as:

- Non-parallel flanges

- Distortion troughs / grooves

- Surface waviness

- Surface scorings

- Other surface imperfections

So, the primary function of a gasket is to create and maintain a seal between flanges, under conditions which may vary markedly from one joint to another, dependent upon the nature and type of application. To meet these varying conditions, a number of flange / fastener / gasket systems have been developed.

Importantly, for all of these systems, the performance of the seal depends upon the interaction of the various elements of the flange joint system [9, 14]. Only when all the components of the system working together in harmony, the seal can be expected to provide a good performance over a reasonable lifetime. The integrity of a safe seal depends upon:

- Selection of correct components appropriate for the application

- Careful preparation, cleaning, installation and assembly

- Correct bolt tightening and loading

- Regular inspection

The behaviour of a flanged joint in service depends on whether or not the tension created in the fasteners will clamp the joint components together with a force great enough to resist failure of the seal, but small enough to avoid damage to the fasteners, joint components, gasket etc. The clamping load on the joint is created on assembly, as the nuts on the fasteners are tightened. This creates tension in the fastener (i.e. preload). Although there may be some plastic deformation in the threads when a fastener is tightened normally, especially on the first tightening, most of the joint components respond elastically as the nuts are tightened. Effectively, the entire system operates as a spring, with the fasteners being stretched and the other joint components being compressed.

e) Working Temperature and Pressure: Temperature will have a significant effect on the sealing performance since hot and cold conditions will degrade the physical properties of the jointing materials and deform them. Sealing material has to withstand maximum and minimum working temperature. Variations in thermal conditions cause the flanges to expand and contract, giving rise to a complex array of lateral forces on the sealing materials. The sealing material must either be able to withstand these lateral forces or the forces must be reduced to an 
acceptable level. Application of the anti-friction coating can also help reduce flanges distortion. The application ranges of sealing materials are given in Figure 7 and Figure 8.

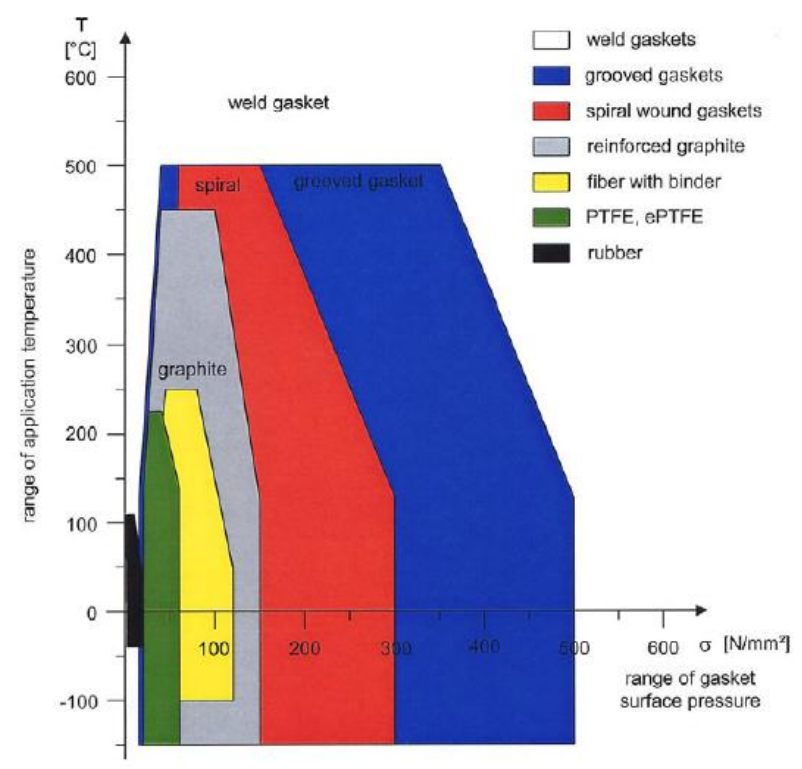

Figure 7. The range of gasket surface pressure limits in relation to the range of temperature for typical gasket types [2]

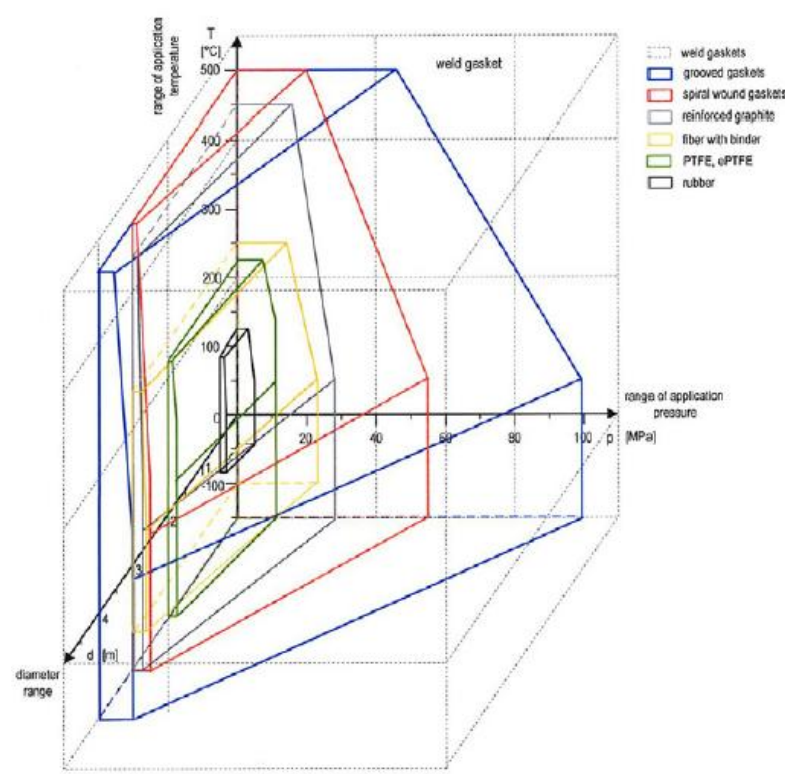

Figure 8. Pressure-temperature range and gasket diameter $(p-T-d)$ for the gasket type or material may be used safely [2]

In maintaining a seal, temperature can never be treated as a completely independent factor. For example, temperature has effect on torque loss. Beyond that, temperature ties in with relative motion of flanges as well as with the chemical considerations in maintaining the initial seal.

As temperature rises from the ambient condition under which a joint assembly is initially tightened, the seal usually improves by a perceptible degree. This can be attributed to a softening effect in the gasket produced by heat. The gasket flows into flange surface imperfections, thereby improving the initial conformation between the gasket and flange.

Prolonged exposure to higher than ambient temperature will cause many non-metallic materials to harden abnormally high temperatures can cause complete breakdown in the initial seal. These are the temperatures which produce burning or charring in non-metallic gaskets. If such conditions exist, preference should be given to high performance fibre-rubber gaskets. [10].

f) Cost: Probably the most important factor considered in any sealing design is cost. However, the cost of the sealing materials, in terms of actual piece price and tooling, should be considered with the cost of other components in the system, that is influenced by seals. In most cases, the cost of the actual sealing technology is infinitesimally small when compared with the investment made in the plant as a whole (Figure 9). Indeed, for many sealing technologies, the cost per unit may be in the region of a few cents, completely insignificant when the total plant costs are considered. 


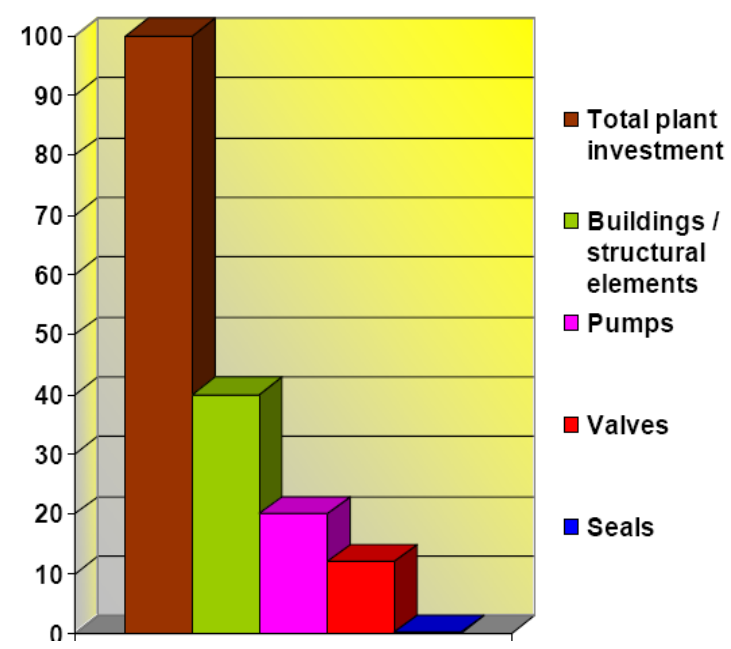

Figure 9. The cost of the sealing technology [2]

Importantly, the unit cost of the sealing technology is overwhelmed completely by the labour costs required to fit the seal, let alone the downtime of the plant. Consequently, the actual cost of the sealing device is immaterial in terms of economic considerations for best available techniques (BAT). However, for the sake of completeness, the following diagram provides an overview of the relative cost of the gasket and the environmental impact of the sealing system (Figure 10).
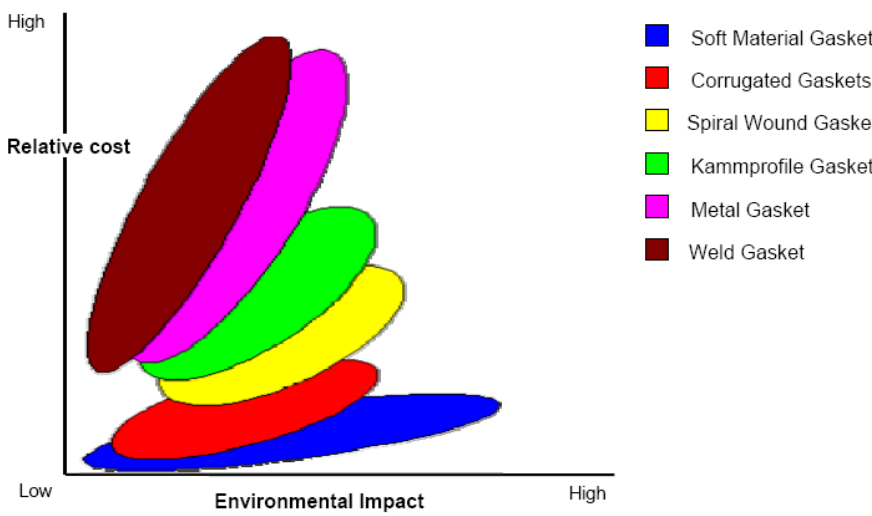

Figure 10. Relative cost of gasket versus environmental impact [2]

Alongside the introduction of asbestos-free gasket materials, there have been many developments for alternative gasket technologies. The following diagrams represent the sealing requirements of the vast majority of process applications.

\section{Conclusions}

It is recognized that industry must reduce its impact on the environment for sustained global development for future generations. A major contributing factor will be through the lowering of industrial emissions, which has been catalysed by a combination of public pressure, environmental legislation and the internal requirement to minimize the loss of valuable feed-stocks. Sealing systems play a vital role in the environmental performance of industrial installations. After careful selection appropriate for the specific application, correct installation, and operation according to the performance envelope, regular inspection and maintenance must be considered for low or zero emission requirements.

As a result, with increasing requirements to reduce industrial emissions, with new sealing technologies, and with new sealing materials requiring more careful selection, handling and installation. Overall, these new materials can outperform their asbestos equivalent, but are usually less forgiving; users must exercise more care in selecting the right material for the job and assembling the seal.

\section{References}

[1]. Sealing Technology-BAT Guidance Notes, European Sealing Association e.V. ESA Publication No: 014/04draft 4, January 2004 
[2]. Guidelines for Safe Seal Usage -Flanges and Gaskets- ESA/FSA Publication No: 009/98 September 1998.

[3]. B. S. ELLIS, "Emission Legislation-Development and Progress", International Seal Forum at Achema '97, Frankfurt, Germany, 9-13 June 1997.

[4]. R. SZWEDA, "Fugitive Emissions: The Matter of Imperfect Seals", Sealing Technology, No: 83, 9-11

[5]. A. C. ALKIDAS, "Combustion-Chamber Crevices: The Major Source of Engine-out Hydrocarbon Emissions under Fully Warmed Conditions", Progress in Energy and Combustion Science, 25 (1999), 253-273.

[6]. I. BROVNICAR, P. PEVEC, Static Industrial Sealing, Donit Tesniti, 1995.

[7]. Non - Metallic Gasketing Handbook, Fluid Sealing Association (FSA), USA.

[8]. A Primer on Cylinder Head Gaskets: Society of Automotive Engineers (SAE) Vol: 88, No: 8, August 1980.

[9]. R. H. WARRING, Seals and Sealing Handbook, Section 2A- Gaskets, Trade\&Technical Press Limited, 1981.

[10]. Gasket Engineering Manual, Armstrong Industry Products Division, USA, 1987.

[11]. R. H. SWICK, “Designing The Leakproof”, Machine Design, January 1976, 100-103

[12]. I. BROVNICAR, F. BERNARD, "New Concepts-New Technologies to Meet New Standards and Customer Requirements", International Seal Forum at Achema '97, Frankfurt, Germany, 9-13 June 1997.

[13]. A. ONAT, "Manufacturing and Characterisation of Composite Static Sealing Materials", PhD Thesis, The Graduate School of Natural and Applied Sciences of Sakarya University (SAU), Metallurgy Engineering \& Materials Science Department, 2000.

[14]. "The Search for a Replacement for Asbestos Gaskets", Sealing Technology, No: 72, 7-9 